\title{
Social Networks and Charitable Giving: Trusting, Doing, Asking, and Alter Primacy
}

\author{
Patricia Snell Herzog ${ }^{1}$ and Song Yang ${ }^{2}$
}

\begin{abstract}
This study examines social networks and financial giving to charitable or religious causes. Conventional social capital measures of general social trust and size of social network are studied as predictors of charitable giving. To these traditional measures, we add an examination of particular network aspects of giving: ego giving in relation to network alters who give, solicitations to give by network ties, and ego soliciting alters to give. Additionally, the study disaggregates alter effects by alter position. Findings indicate that, net of social trust, social network factors significantly predict likelihood of being a giver. In particular, findings are that egos are especially likely to be donors when their primary alter donates. Three configurations of ego-alter giving and solicitations are significant predictors of ego giving, indicating that ego-alter doing matters more than asking. Theoretical contributions for relational and prosocial studies are discussed, as are practical implications for fundraising professionals.
\end{abstract}

Keywords: charitable giving, social networks, social capital, social theory, altruism

Charitable giving by individuals is an important social phenomenon that is to date understudied by sociologists. Giving USA (2015) estimates that giving to charitable sources amounts to nearly $\$ 316$ billion and accounts for nearly two-thirds of all charitable contributions - including those from foundations, bequests, and corporations. The largest proportion of the total, 72 percent and $\$ 229$ billion, is given by individuals. The average amount of money that individuals donate to charity each year has generally risen over time. Despite recent recession setbacks and adjusting for inflation, individual contributions today far exceed what they were 30 years ago. Thus, individual charitable contributions are an increasingly significant aspect of social life that deserves sociological investigation.

\footnotetext{
${ }^{1}$ Patricia Snell Herzog, University of Arkansas, Department of Sociology and Criminology, 210 Old Main Building, Fayetteville, AR, USA Phone: 479.575.3779 Email: herzog@uark.edu *Corresponding author

${ }^{2}$ Song Yang, University of Arkansas, Department of Sociology and Criminology, 210 Old Main Building, Fayetteville, AR, USA Phone: 479.575.3748 Email: yangwang@uark.edu
} 
What explains charitable giving by individuals? A plethora of literature on charitable giving exists within fields related to economics and, to a lesser extent, psychology. Given the rational actor understanding of charitable giving that is typical to these areas, the persistent puzzle is why people act against their own self-interest to benefit others (Wang \& Graddy, 2008). The available social psychological explanations tend to focus on internal motivations, or external and situational factors, or a combination of those (Simpson \& Willer, 2015). However, scholars find that there is heterogeneity in social psychological predictors of prosocial behaviors (Simpson \& Willer, 2008), raising questions about their explanations.

Sociology furnishes many insights on prosocial action, but under divergent theoretical expectations. Both Simmel (Simmel, 1964; Pescosolido \& Rubin, 2000) and Durkheim (1915) posit that network influence and social solidarity are key forces in social actions, particularly those oriented toward altruistic and moral ends. However, Durkheim saw social solidarity as declining in modernity due to social differentiation, while Simmel—especially as interpreted by Fischer (1995) — saw modern people as still embedded in webs of affiliation. This should raise curiosity around the empirical case of charitable giving as a way to adjudicate between the Durkheimian, individualistic expectation that social relations are now unlikely to predict individual behavior, such as charitable giving, or the Simmelian relational expectation that affiliations remain an important predictor of behavior. Mounting empirical evidence confirms theoretical expectations that social factors help to differentiate giving behaviors (Putnam et al., 2012; Lim \& MacGregor, 2012; Bekkers \& Weipking, 2011a; 2011b; Lim \& Putnam, 2010; Brooks, 2005). Despite these advancements, it remains understudied which particular aspects of social networks matter in charitable giving. 
This study investigates charitable giving through a disaggregated social capital approach that focuses on social affiliations via egocentric networks. A contribution of the study is the disaggregation of network effects by alter position. Another novel contribution is an investigation of ego-alter network configurations, namely whether ego and alter are givers, whether ego asks alter to give, whether alter asks ego to give, and their combinations. We undertake these approaches to investigate the primary research question of this study: Which specific aspects of social capital differentiate who donates money to charitable causes? We also ask: What role do social network ties have in distinguishing who is a giver and who is not?

\section{Social Networks and Charitable Giving}

In explaining prosocial behaviors, scholars are increasingly moving beyond purely economic, rational actor explanations for charitable giving, and generally findings indicate that socio-relational factors partially account for actions oriented toward improving the collective good (Forbes \& Zampelli, 2011). Among the most notorious of such studies are those about social capital (e.g. Putnam, 2000), with findings that having higher levels of social capital relates to greater prosocial behaviors, such as philanthropy (Brown \& Ferris, 2007), volunteering (Taniguchi \& Marshall, 2014; Musick et al., 2000), religious participation (Putnam et al., 2012), and online giving (Reddick \& Ponomariov, 2013).

Social networks have attracted burgeoning attention, and there has been a notable increase in social network findings in numerous subfields and disciplines (Rivera et al., 2010; Glanville et al., 2013). Likewise, many scholars have recently investigated the general role of social networks in predicting prosocial behaviors, such as altruism, cooperation (Simpson \& Willer, 2015), volunteering (Paik \& Navarre-Jackson, 2011), political participation (Yen \& Zampelli, 2014), and charitable giving (Lewis et al., 2013). These include studies of number of 
friends (Curry \& Dunbar, 2011), kinship support and the expectation for reciprocal altruism (Curry et al., 2013), family member influence to volunteer (Nesbit, 2013), religious participation (Lewis et al., 2013), and recruitment (Merino, 2014).

However, with a few notable exceptions (Castillo et al., 2014; Saxton \& Wang, 2013; Hustinx et al., 2012; Ostrander, 2007), the role of social networks in the specific social capital outcome of financial giving is understudied. Yet, there is mounting evidence that social networks are key in understanding charitable giving. For example, Cook (2005) finds that social networks underlie the ways in which people mobilize resources for cooperation. When investigating social trust and social networks in the same study, scholars find social networks to be a major factor predicting charitable behaviors (Wang \& Graddy, 2008). Considering evidence that various expressions of social capital may be distinct in their predictors (Hustinx et al., 2012), the link between social capital and financial giving specifically warrants investigation. Yet a number of unanswered questions remain with regard to applying a contemporary understanding of social capital. What is missing is a nuanced study that investigates which particular features of social networks are significant predictors of charitable giving. This study thus advances prior efforts

\section{Hypotheses}

Based on extant studies, our first two hypotheses highlight conventional aspects of social capital: social trust and network size (Putnam, 2000; Curry \& Dunbar, 2011). We investigate in the first hypothesis the expectation that more trust is related to greater likelihood of being a charitable giver (e.g. Glanville et al. 2013; Taniguchi and Marshall 2014). Thus, we formulate Hypothesis 1: Social trust positively predicts likelihood of charitable giving. We also investigate the expectation that greater social network size, net of trust, will relate to greater likelihood of being a charitable giver. Thus, we formulate Hypothesis 2: Social network size positively 
predicts likelihood of charitable giving. In addition to using these two general measures of social capital, we investigate networks in greater detail by studying which features of networks matter.

Studies indicate that social networks influence giving because they expose people to “doing" behavior (e.g. Frey \& Meier, 2004). Information on the actions of others can invoke social comparison that becomes a reference in making decisions about one's own actions (Andreoni \& Petrie, 2004). For example, research participants in an experiment gave the greatest charitable contribution when the other research participants were identified and their giving amounts were reported. The theory is that social comparison overcomes the "free rider problem," which is that people have a tendency to relay on the actions of others unless information triggers their needing to have a personal role. In another study, information on the giving contributions of others increased contributions by 12 percent (Shang \& Croson, 2009). Based on these studies, we expect that people with alters who give to charitable causes are more likely to give. We formulate Hypothesis 3: Network "doing” positively predicts likelihood of charitable giving.

Our fourth hypothesis is based on other studies that investigate the role of solicitations to give, or "asks," by alters (e.g. Bekkers \& Wiepking, 2011a). For example, one study found that people with more extended networks and higher education give more, but that this is mediated by requests for donations, along with financial resources, church attendance, and prosocial personality characteristics (Wiepking \& Maas, 2009). Another, on volunteering, found that prosocial activities were higher when recruitment was greater (Paik \& Navarre-Jackson, 2011). A third study found the likelihood of giving is 10 times higher and donation size 52 percent larger when friends ask for donations (Castillo et al., 2014). One theory for why this relationship exists is peer pressure, that desire to present as a generous person and compels giving (Meer, 2011). Another theory is that giving is part of social support generally, and that people are likely 
to act generously when compelled to support their network through being asked (Merino, 2014).

In both theories, the observable result is the same: network asking is linked to greater giving. Based on this vein of studies, we formulate Hypothesis 4: Network "asking” positively predicts likelihood of charitable giving.

\section{Methodology}

Data. To test these hypotheses, we employ data from the 2010 Science of Generosity Survey, a national survey of Americans ages 23 and older who live in U.S. households (Smith et al., 2010). The sample used for the survey is a probability-based, online, non-volunteer access panel sample drawn using a dual-frame sampling method that was partly recruited through an address-based sample method and partly by telephone using random-digit-dialing (RDD) methods. This dual-sampling frame captures cell phone-only households as well as households without internet access and Spanish-speaking households. The combination of address-based sampling (ABS) and telephone random-digit-dial (RDD) methods accounts for about 99 percent

of the U.S. population. Households without computers were provided with laptops and immediate internet access. Respondents received token incentives in order to ensure greater representation across the socioeconomic spectrum. The sample was randomly selected for the survey using an implicitly stratified systematic sample designed to be a nationally representative sample of respondents. A final sample size of 1,997 was achieved for the survey, with a 66 percent participation rate. Population characteristics are compared to benchmark datasets and reflect limited differences between the general U.S. population and the study sample. Statistical weights are employed to adjust for sampling and population representation. Thus, the weighted survey data represent a nationally representative sample of Americans ages 23 and older. 
Measures. The outcome measure is a binary variable representing whether respondent gave to charitable causes in the past year. To investigate Hypothesis 1, that social trust is related to giving, a seven-point strongly dis/agree scale is used for the statement "Generally speaking, most people can be trusted." The survey produced ego-centric network data by asking, "In the last 12 months, how many adults have you felt close to, including a spouse or romantic partner, adult children, or other adult family members, friends, neighbors, coworkers, or people involved in groups or organizations that you are involved in?" Respondents ("egos") could nominate zero to four, or select five or more, representing the number of network ties and a test of Hypothesis 2.

For each of the social ties named ("alters"), the survey asked an array of questions. Respondents were asked whether each alter gives money to charitable causes, indicating social network "doing," labeled as Network Gives, and providing a test of Hypothesis 3. Given the consistent evidence that social networks influence social outcomes through exposing individuals to others' behavior and thus establishing normative expectations, we investigate social network doing as an exposure effect which is a binary outcome of any alter in the network exposing ego to giving. We also investigate the possibility that the position of alters may matter in network dynamics (Fowler \& Christakis, 2010) by disaggregating alter position in studying whether Alter 1, Alter 2, Alter 3, Alter 4, and Alter 5 each gives to charitable or religious causes.

Hypothesis 4 is tested by a measure of whether each alter had ever asked the respondent to give, labeled as Network Asks. We again examine this as exposure to any social network member soliciting the ego to give, and as a positional effect of each alter asking ego to give. Respondents were also asked if they had ever asked each alter to give, labeled as Network Asked. These data also allow an operationalization of ego-alter giving combinations: whether the alter gives, asks ego to give, or has been asked by ego to give can vary in tandem. Together these 
three measures give rise to eight possible scenarios, which are listed in Table 5, and which we investigate in their relation to ego giving. We also investigate a number of potential covariates, including age (Lewis et al., 2013; Merino, 2013; Wiepking \& Maas, 2009), religious participation (Cnaan \& Curtis, 2013; Wiepking \& James, 2013; Bekkers \& Schuyt, 2008), political affiliation (Putnam et al., 2012), income (Wiepking \& Maas, 2009), education, homeownership, marital status, employment status, gender, and race (Bekkers \& Weipking, 2011a; 2011b). We include the alter covariates of age, marital status (Aral \& Walker, 2012), gender (Einolf, 2011), and education (Gesthuizen \& Scheepers, 2012).

Analysis. Statistical modeling is computed using STATA 14 survey commands (O’Donnell et al., 2008). Measures included in each model are tested for multicolinearity, with maximum variance inflation factor below three and tolerance above 0.50 . Regression diagnostics are computed post-estimation to test model specification and Hosmer-Lemeshow goodness-of-fit (Fagerland \& Hosmer, 2012). Nested models are tested using Wald tests. Table 1 presents descriptive statistics for all measures. Logistic regression analyses predicting the binary outcome of giving or not giving are presented in Tables 2-5. In Table 2 models, there are 20 cases missing for one of the independent measures (1 percent) that were listwise deleted, resulting in a sample size of 1,977 . There were 137 cases (6.9 percent of the sample) that answered that they have zero people to whom they feel close. Since these respondents do not have a social network grid, they are excluded from Model 4 in Table 2 onward, resulting in a sample size of 1,840. Table 4 examines alter positions and restricts to the 1,208 cases ( 60.5 percent) who enumerated five alters, of which 16 cases were missing on the independent, resulting in a sample size of 1,192.

[Insert Table 1 Here] 
Limitations. Despite the strengths of our approach, this study also has some limitations. First, all results report social network factors as related to whether ego is a giver, not amounts of money donated. Second, our findings rely on self-reported survey data susceptible to potential respondent errors (Paik \& Sanchagrin, 2013), though this study limited these issues by reducing fatigue via an online, skip-pattern survey. Third, endogeneity of social network influences with the charitable giving outcome is a possibility. To assess and limit this issue, we considered three possible sources of endogeneity: omitted variables, self-selection, and simultaneity. In investigating the possibility of an omitted variable, we conducted additional analyses that included measures for: Alter 1 is a source of emotional support for ego; Alter 1 discusses with ego social or political issues; Alter 1 agrees with ego on social and political issues; Alter 1 is religious; Alter 1 is close in age to ego; and the number of years that ego has known Alter 1. None of these were statistically significant, and their inclusion failed the nested model test.

We additionally considered self-selection effects in the homophily of social networks, which we conceive of theoretically as considering whether "birds of a similar feather flock together" or rather that "birds in similar weather grow a similar feather." The most direct investigation of this possibility would be to include in the survey a measure for the duration that ego and alters have known each other, along with a duration that ego has been giving, and ideally even duration that alters have been giving. In the current dataset, only duration of ego-alter relationship exists, and thus we recommend this as a topic for future studies. We were able with this dataset to investigate proxy measures for alter ties. Specifically, we analyzed Model 1 of Table 4 with three alter type categories: ties that likely pre-date adult giving behaviors (parents and other family members; Wilhelm et al., 2008); spouses (Herzog \& Price, 2016); and ties that 
likely are concurrent to or post-date giving (neighbors and all other non-family, non-spousal ties; Putnam 2000; Putnam et al. 2012; McPherson et al. 2011).

Employing family ties as the reference group, we find that the alter giving correlation remains statistically significant, that there is no statistically significant difference for spouse and non-family alters (as compared to parent and family alters), and that the model fails nested model test. We do find that there are differences of interest, however, for Model 1 in Table 5. By including the alter types in the model, we find that the mutual asking scenario remains statistically significant for family alters, but is not statistically significant for spouses or alters who are not family (neighbors and others). This implies that in family relationships when both ego and alter ask each other to give, ego is more likely to be a giver. Though these are not longitudinal data, there is a high likelihood that in non-spousal family ties ego learned this behavior from alter.

There are remaining ambiguities in these proxies regarding the timing of tie formation, especially given increasing family fluidity among younger generations (Cherlin 2014). However, for the purposes of this analysis we assume for now that newer family ties would likely not be among the top five of alters nominated, and we also suggest future studies investigate this empirically. In the interim, we offer a step forward in assessing the possible direction of influence. Moreover, a third possible source of endogeneity, simultaneity, requires longitudinal data that is coupled with similar social network measures, to investigate social networks as dynamic and mutually influencing over time. Nevertheless, this study contributes important insights in studying social networks and giving.

\section{Results}


Social Trust and Network Size. We first examine potential relationships of individual charitable giving with general social trust and social network size. Table 2 presents findings from the first four models. Model 1 in this table predicts the likelihood of being a giver by including typical demographic and social status measures as covariates. Model 1 shows that annual household income is highly statistically significant (at the $\mathrm{p}<0.001$ level) and positively related to being a giver, with the odds of being a giver increasing by 1.09 for each unit increase in income (about every \$5,000). Also statistically significant are gender, age, educational attainment, political party, and religious service attendance. The odds of being a giver are 1.38 for females, as compared to men, and the odds of being a giver increase by 1.01 for each year of age. The odds of someone with a college degree being a giver are 1.58 greater than for without a college degree. A Democrat has 1.62 greater odds of being a giver, as compared to no political party affiliation. Those attending religious services weekly or more have 1.47 greater odds of being a giver than those who never attend.

[Insert Table 2 Here]

Model 2 in Table 2 tests Hypothesis 1 that, net of the aforementioned covariates, social trust positively predicts likelihood of being a giver (the same model represents the baseline model for all subsequent tables). The results support Hypothesis 1 and show that generalized social trust is statistically significantly related to being a charitable giver, with the odds of being a giver increasing by 1.10 for each unit increase in the level of social trust. Yet the nested model Wald test shows that Model 2 is only slightly statistically significantly $(\mathrm{p}<0.05)$ distinct from Model 1, implying that social trust's contribution to giving is minimal.

Model 3 adds social network size to test Hypothesis 2. Findings indicate that network size is statistically significantly and positively related to being a giver; the odds of giving 
increase by 1.19 for each friend listed in the egocentric network. This provides initial support for Hypothesis 2 . The nested model Wald test shows that Model 3 is statistically significantly $(\mathrm{p}<0.0001)$ distinct from Model 2, with a significant contribution gained from adding social networks to the model. However, it remains unclear whether it is social network size or simply whether one has a social network that matters, a question we investigate in Models 3 (network size) and 4 (having a network). Model 4 presents the previous model restricted to the respondents who listed at least one friend in their social network $(n=1,840)$. The fact that the statistical significance of the network size measure is lost with this constriction indicates that it is not the relative size of the social network, but rather whether one has a social network at all that predicts being a giver. Thus, while we find initial support for Hypotheses 1 and 2, Table 2 shows that further investigation is needed into particular aspects of network ties.

Network Doing and Asking. Table 3 presents the results of the sample in Model 4 of Table 2, those respondents who named at least one person to whom they feel close. All the same covariates of Table 2 are included in subsequent models, but only statistically significant predictors are shown in the table. In Table 3, Model 1 includes whether an ego has a social network tie who gives to charitable causes (Giving in Social Network-Hypothesis 3: Giving "Doing"), while Model 2 analyzes whether an ego has been asked by a social tie to give money to charity (Asked by Social Network to Give-Hypothesis 4: Giving “Asking”). Model 3 includes whether ego asked any of their social network ties to donate to charitable causes (Asks Social Network to Give - Giving “Asks”). Model 4 tests all three measures (Giving, Asked, and Asks). [Insert Table 3 Here]

Findings indicate that the same covariates retain statistical significance, with the one exception that white respondents, as compared to black respondents and net of having at least 
one social tie, are statistically significantly more likely to give to charitable causes. Model 1 shows that Americans with at least one giver in their network are statistically significantly more likely to be givers, with an odds ratio 1.86 greater than those without a giver in their network. This result provides initial support for Hypothesis 3. Support is also found for Hypothesis 4. Americans with a social network tie who asked them to give to charitable causes (Model 2) are also statistically significantly more likely to be givers, with 1.71 greater odds than those without an asker in their network. Model 3 shows that Americans who asked someone in their social network to give to causes have 1.57 greater odds of being a giver than those who did not.

In the final model of Table 3, Model 4 analyzes all three of these measures simultaneously. It confirms that, on average, Americans with givers in their network are more likely to give than those without. Notably, once all three giving network measures are includedgiving in network, asked to give by network, and ask network to give - the only measure that retains statistical significance is the first: those exposed to a giver have an odds ratio of 1.64 greater likelihood of someone without a giver in their network. Likewise, estimating the models as nested with each social network measure added sequentially returned statistically significant results only for Models 1 and 4, evidencing nil contribution of the asked and asks measures. Thus, Table 3 provides evidence that most supports Hypothesis 3, that exposure to giving within social networks is related to greater likelihood of being a giver. At the level of the social network as a whole, it appears that it is exposure to givers, not necessarily solicitations or asking network members to give, that relates to greater odds of being a giver.

Network Exposure and Position. In Table 4, the models follow a similar structure to the previous set, with the central difference that each alter is entered in the model individually, instead of being combined into an overall social network. The same measures are analyzed, but 
they are specifically related to each alter position. All prior covariates are included, and only those with statistical significance are displayed in Table 4. Most covariate significance remains the same, with some exceptions explained below. Model 1 of Table 4 again focuses on Alter 1, which is statistically significantly related to a greater likelihood of ego giving. When Alter 1 gives, ego has 1.54 greater odds of giving than if Alter 1 is not a giver. None of the other alter positions are statistically significant.

[Insert Table 4 Here]

In Model 2, a similar effect is found for being asked to give, namely that Alter 1 is the only statistically significant predictor among the five alter positions. When Alter 1 asks ego to give, the odds are 1.68 greater that ego is a giver than when Alter 1 does not. In Model 3, a different pattern emerges: Alter 1 does not have a statistically significant relationship to ego giving. Instead, it is Alter 3 that is significant. However, in this case, it appears that asking Alter 3 to give decreases the odds that ego is a giver by half. Thus, more evidence is found to support network cascades in giving behavior, through the position of alters relating to ego giving. Likewise, Wald tests of nested models by alter position indicate that only the model with Alter 1 measures included is statistically significantly $(\mathrm{p}<0.05)$ distinct from the baseline model. A single model with all the alters fails the nested model test, and other robustness checks of the Alter 3 finding failed. Therefore, the primary alter position (Alter 1) is the only one that consistently and robustly relates to ego giving.

Model 4 thus examines the likelihood of being a giver when only Alter 1 giving characteristics are included in the model. Specifically, Model 4 investigates ego covariates and Alter 1 Gives, Alter 1 Asked (alter asked ego to give), and Alter 1 Asks (ego asks alter to give) in predicting likelihood that ego is a giver to charitable causes. This model shows that, on 
average and net of covariates, Americans whose primary network tie is a giver have 1.45 greater odds of being a giver than those whose primary network tie is not a giver. Of note is that asked and asks are not statistically significant net of Alter 1 gives. Also, ego being female and older become statistically significant predictors once alter giving is controlled, while the statistical significance of being a political independent and having greater social trust is eliminated with inclusion of alter giving factors. The findings of Model 4 provide further support for Hypothesis 3 , and further, they identify that it is giving behavior by primary alters that relates to ego giving.

Doing-Asking Combinations. The final set of analyses is presented in Table 5. All covariates of the baseline model (Table 2, Model 2) are included, and only statistically significant predictors are displayed. This set of models examines combinations of alter giving and ego-alter asking. The eight possible scenarios are: (1) alter gives and mutual asking, (2) alter gives and alter asks, (3) alter gives and ego asks, (4) alter gives and no asking, (5) non-giving alter and mutual asking, (6) non-giving alter and alter asks, (7) non-giving alter and ego asks, and (8) non-giving alter and no asking (reference category). The eighth scenario (non-giving alter and no asking) is the reference category and represents the largest group: 47.61 percent. Table 5 displays the results.

\section{[Insert Table 5 Here]}

Model 1 in Table 5 displays the results of including eight scenarios with all previous covariates and finds that those with an Alter 1 in any of three scenarios are statistically significantly more likely to be givers than those whose alter is in Scenario 8. These are: Scenario 1: Alter Gives and Mutual Asking; Scenario 2: Alter Gives and Alter Asks; and Scenario 4: Alter Gives and No Asking. Of these, Scenario 2: Alter Gives and Alter Asks has the greatest likelihood of ego being a giver, with 2.52 greater odds of being a giver, as compared to the 
reference category. Scenario 1: Alter Gives and Mutual Asking has the second largest odds ratio, with 2.02 greater odds of being a giver, compared to the reference category. Of the three statistically significant scenarios, the most common occurrence is Scenario 4: Alter Gives and No Asking, yet it has the lowest odds ratio for ego being a giver: with odds of being a giver as 1.88 greater than for Americans with no network giving dynamics, as compared to reference. We thus find further evidence in support of Hypothesis 3, and for a nuanced version of Hypothesis 4.

\section{Discussion and Implications}

This study contributes to a better understanding of individual charitable activity choices. Specifically, we examined how one's close relations regarding charitable giving influence one's own donative behavior. Beyond social trust alone, we find that social network factors differentiate who gives to charitable and religious causes. In answering calls by scholars such as Curry and Dunbar (2011) for investigations into specific features of social networks, we focus in particular on size, alter position, exposure to giving behaviors within networks, solicitations to give by network ties, ego and alter behavioral pairings, and mechanisms of social network effects via relational characteristics. We find that alters can have an impact on ego's choice to give. Based on the insights of Fowler and Christakis (2010), we investigated positions of alters and find that the impact is not uniform across all alters.

Only the donation behavior of the person listed in the first alter position consistently and robustly related to greater likelihood that ego engages in philanthropic giving. We additionally conclude that social network "doing" and "asking" are both important social network features. Both having a giver and an asker in one's social network increase the likelihood that one participates in charitable giving. When analyzing both simultaneously, we find that having a giver in the set of alters has a larger impact than network asking. We also find that the 
configuration of ego-alter asking and giving matters. Individual charitable giving is related to three configurations: mutual doing and mutual asking, mutual doing and alter asking, and mutual doing without either asking. These findings have implications for scholarship on philanthropy, as well as for practitioners in the fundraising industry.

Contributions to Scholarship. This study underscores recent and developing theories on the significance of relations in altruistic and prosocial behaviors (e.g. Simpson \& Willer, 2015). One theoretical contribution is its investigation into complex constellations of relational configurations. We provide an empirical instantiation of the theories by Donati and Archer (2015), who argue that epistemology is necessarily dependent upon relational understandings of social occurrences. While symbolic interactionism has long emphasized the social process behind perception and meaning-making (Mead, 1934), this newer articulation of the social interdependency of meaning-making highlights both micro, meso, and macro-level interactions, which are engrained in the social structure via features such as social networks. The evidence here is that givers are embedded in social structural relations: more tied to givers and askers. More generally, these findings challenge a purely agentic, rational choice theory and a purely situational theory of social action: in social networks, micro-level agency interacts in complex ways with macro-level social structures. We apply a Simmelian notion of webs of affiliation (Pescosolido \& Rubin, 2000; Simmel, 1964) to extend and, in certain ways, contradict Durkheimian notions of altruism, social solidarity, and morality (Durkheim, 1915). This study highlights the continued relevance of Durkheim's notion of individuals as performing self-costly behaviors, such as giving away their monetary resources to nonprofit and religious organizations, in order to sustain and promote social goods, such as the strength of their interpersonal relationships. Yet the study also provides counter-evidence to Durkheim's claim that modernity 
brought continual decline in social forces (Tole, 1993), resulting in a rising sense of individualism (e.g Bellah et al., 1985), because it evidences a continued social patterning.

Contributions to Practice. This study also has a number of practical implications and could be employed to leverage further donations by using relations of one donor to seek donations from their network. For example, we discovered that Alter 1 is primary, which supports existing findings (Rivera e al., 2010) on the importance of dyadic relationships. We also contribute additional support for social networks as part of explaining religious giving, insofar as religious people may give with greater frequency because of being exposed to more observations of giving, and solicitations, in their network (Wiepking \& Maas, 2009; Lewis et al., 2013; Lim \& MacGregor, 2012), although that may be in decline (Taylor, 2014). Moreover, our findings have relevance for research-based philanthropy: targeting individuals may not be as effective as strategies that seek to increase giving through network ties.

\section{References}

Andreoni, J., \& Petrie, R. (2004). Public goods experiments without confidentiality: a glimpse into fund-raising. Journal of Public Economics, 88(7-8), 1605-1623.

Aral, S., \& Walker, D. (2012). Identifying influential and susceptible members of social networks. Science, 337(6092), 337-341.

Bekkers, R., \& Wiepking, P. (2011a). A literature review of empirical studies of philanthropy: Eight mechanisms that drive charitable giving. Nonprofit and Voluntary Sector Quarterly, 40(5), 924-973.

Bekkers, R., \& Wiepking, P. (2011b). Who gives? A literature review of predictors of charitable giving, part one: Religion, education, age and socialisation. Voluntary Sector Review, 2(3), 337-365. 
Bellah, E. R. N., Madsen, R., Sullivan, W. M., Swidler, A., \& Tipton, S. M. (1985). Habits of the heart: Individualism and commitment in American life. University of California Press.

Brooks, A. C. (2005). Does social capital make you generous? Social Science Quarterly, 86(1), $1-15$.

Brown, E., \& Ferris, J. M. (2007). Social capital and philanthropy: An analysis of the impact of social capital on individual giving and volunteering. Nonprofit and Voluntary Sector Quarterly, 36(1), 85-99.

Castillo, M., Petrie, R., \& Wardell, C. (2014). Fundraising through online social networks: A field experiment on peer-to-peer solicitation. Journal of Public Economics, 114, 29-35.

Cherlin, A. J. (2014). Labor's love lost: The rise and fall of the working-class family in America. New York: Russell Sage Foundation.

Cnaan, R. A., \& Curtis, D. W. (2013). Religious congregations as voluntary associations: An overview. Nonprofit and Voluntary Sector Quarterly, 42(1), 7-33.

Cook, K. S. (2005). Networks, norms, and trust: The social psychology of social capital. 2004 Cooley Mead Award Address. Social Psychology Quarterly, 68(1), 4-14.

Curry, O., \& Dunbar, R. I. M. (2011). Altruism in networks: The effect of connections. Biology Letters 7, 651-653.

Curry, O., Roberts, S. G. B., \& Dunbar, R. I. M. (2013). Altruism in social networks: Evidence for a "kinship premium." British Journal of Psychology, 104(2), 283-295.

Donati, P., \& Archer, M. S. (2015). The Relational Subject. Cambridge University Press.

Durkheim, E. (1915). The Elementary Forms of the Religious Life. New York: Free Press.

Einolf, C. J. (2011). Correlates of volunteerism and charitable giving in the 50 United States. Nonprofit \& Voluntary Sector Quarterly, 40(6), 1092-1112. 
Fagerland, M. W., \& Hosmer, D. W. (2012). A generalized Hosmer-Lemeshow goodness-of-fit test for multinomial logistic regression models. The Stata Journal, 12(3), 447-453.

Fischer, C. S. (1995). The subcultural theory of urbanism: A twentieth-year assessment. American Journal of Sociology, 101(3): 543-577.

Forbes, K. F., \& Zampelli, E. M. (2011). An assessment of alternative structural models of philanthropic behavior. Nonprofit and Voluntary Sector Quarterly, 40(6), 1148-1167.

Forbes, K. F., \& Zampelli, E. M. (2014). Volunteerism: The influences of social, religious, and human capital. Nonprofit \& Voluntary Sector Quarterly, 43(2), 227-253.

Fowler, J. H., \& Christakis, N. A. (2010). Cooperative behavior cascades in human social networks. Proceedings of the National Academy of Sciences, 107(12), 5334-5338.

Frey, B., \& Meier, S. (2004). Prosocial behavior in a natural setting. Journal of Economic Behavior \& Organization, 54(1), 65-88.

Gesthuizen, M., \& Scheepers, P. (2012). Educational differences in volunteering in crossnational perspective: Individual and contextual explanations. Nonprofit \& Voluntary Sector Quarterly, 41(1), 58-81.

Giving USA. (2015). Annual report on philanthropy for the year 2014. Indianapolis, IN: Lilly Family School of Philanthropy, Indiana University.

Glanville, J. L., Andersson, M. A., \& Paxton, P. (2013). Do social connections create trust? An examination using new longitudinal data. Social Forces, 92(2), 545-562.

Hampton, K., \& Wellman, B. (2003). Neighboring in Netville: How the Internet supports community and social capital in a wired suburb. City \& Community, 2(4), 277-311.

Herzog, P. S., \& Price, H. E. (2016). American generosity: Who gives and why. New York: Oxford University Press. 
Hustinx, L., Van den Bosch, D., \& Delcour, C. (2012). Money makes the world go round: Voluntary associations, financial support, and social capital in Belgium. Nonprofit \& Voluntary Sector Quarterly, 42(6), 1176-1196.

Lewis, V. A., MacGregor, C. A., \& Putnam, R. D. (2013). Religion, networks, and neighborliness: The impact of religious social networks on civic engagement. Social Science Research, 42(2), 331-346.

Lim, C., \& MacGregor, C. A. (2012). Religion and volunteering in context: Disentangling the contextual effects of religion on voluntary behavior. American Sociological Review, 77(5), 747-779.

Lim, C., \& Putnam, R. D. (2010). Religion, social networks, and life satisfaction. American Sociological Review, 75(6), 914-933.

McPherson, M., Smith-Lovin, L., \& Cook, J. M. (2001). Birds of a feather: Homophily in social networks. Annual Review of Sociology, 27(1), 415-444.

Mead, G. H. (1934). Mind, self, and society. Chicago, IL: University of Chicago Press.

Meer, J. (2011). Brother, can you spare a dime? Peer pressure in charitable solicitation. Journal of Public Economics, 95(7-8), 926-941.

Merino, S. M. (2014). Social support and the religious dimensions of close ties. Journal for the Scientific Study of Religion, 53(3), 595-612.

Musick, M. A., Wilson, J., \& Bynum, W. B. (2000). Race and formal volunteering: The differential effects of class and religion. Social Forces, 78(4), 1539-1570.

O’Donnell, O., van Doorslaer, E., Wagstaff, A., \& Lindelow, M. (2008). Analyzing health equity using household survey data: A guide to techniques and their implementation. Washington, D.C: World Bank. 
Ostrander, S. A. (2007). The growth of donor control: Revisiting the social relations of philanthropy. Nonprofit \& Voluntary Sector Quarterly, 36(2), 356-372.

Paik, A., \& Navarre-Jackson, L. (2011). Social networks, recruitment, and volunteering: Are social capital effects conditional on recruitment? Nonprofit \& Voluntary Sector Quarterly, 40(3), 476-496.

Paik, A., \& Sanchagrin, K. (2013). Social isolation in America: An artifact. American Sociological Review, 78(3), 339-360.

Pescosolido, B. A., \& Rubin, B. A. (2000). The web of group affiliations revisited: Social life, postmodernism, and sociology. American Sociological Review, 65(1), 52-76.

Putnam, R. D. (2000). Bowling alone: The collapse and revival of American community. New York: Simon \& Schuster.

Putnam, R. D., Campbell, D. E., \& Garrett, S. R. (2012). American grace: How religion divides and unites us. New York: Simon \& Schuster.

Reddick, C. G., \& Ponomariov, B. (2013). The effect of individuals' organization affiliation on their internet donations. Nonprofit \& Voluntary Sector Quarterly, 42(6), 1197-1223.

Rivera, M. T., Soderstrom, S. B., \& Uzzi, B. (2010). Dynamics of dyads in social networks: Assortative, relational, and proximity mechanisms. Annual Review of Sociology, 36(1), $91-115$.

Saxton, G. D., \& Wang, L. (2013). The social network effect: The determinants of giving through social media. Nonprofit and Voluntary Sector Quarterly, 43(5): 850-868.

Shang, J., \& Croson, R. (2009). A field experiment in charitable contribution: The impact of social information on the voluntary provision of public goods. The Economic Journal, $119(540), 1422-1439$. 
Simmel, G. (1964). Conflict and the web of group affiliations. New York: Free Press.

Simpson, B., \& Willer, R. (2008). Altruism and indirect reciprocity: The interaction of person and situation in prosocial behavior. Social Psychology Quarterly, 71(1), 37-52.

Simpson, B., \& Willer, R. (2015). Beyond altruism: Sociological foundations of cooperation and prosocial behavior. Annual Review of Sociology, 41(1), 43-63.

Smith, C., Herzog, P. S., \& Beyerlein, K. (2010). Methods report and user's guide to the 2010 Science of Generosity Survey. University of Notre Dame.

Stern, M. J., \& Dillman, D. A. (2006). Community participation, social ties, and use of the Internet. City \& Community, 5(4), 409-424.

Taniguchi, H., \& Marshall, G. (2014). The effects of social trust and institutional trust on formal volunteering and charitable giving in Japan. Voluntas: International Journal of Voluntary \& Nonprofit Organizations, 25(1), 150-175.

Taylor, P., \& Center, P. R. (2014). The next America: Boomers, Millennials, and the looming generational showdown. New York: Public Affairs.

Tole, L. A. (1993). Durkheim on religion and moral community in modernity. Sociological Inquiry, 63(1), 1-29.

Wang, L., \& Graddy, E. (2008). Social capital, volunteering, and charitable giving. Voluntas: International Journal of Voluntary \& Nonprofit Organizations, 19(1), 23-42.

Wiepking, P., \& James, R. N. (2013). Why are the oldest old less generous? Explanations for the unexpected age-related drop in charitable giving. Ageing and Society, 33(3), 486-510.

Wiepking, P., \& Maas, I. (2009). Resources that make you generous: Effects of social and human resources on charitable giving. Social Forces, 87(4), 1973-1995. 
Wilhelm, M. O., Brown, E., Rooney, P. M., \& Steinberg, R. (2008). The intergenerational transmission of generosity. Journal of Public Economics, 92(10-11), 2146-2156.

Yen, S. T., \& Zampelli, E. M. (2014). What drives charitable donations of time and money? The roles of political ideology, religiosity, and involvement. Journal of Behavioral and Experimental Economics, 50, 58-67. 


\section{Author Biographies}

Patricia Snell Herzog is an assistant professor in the Department of Sociology and Criminology and Co-Director of the Center for Social Research, as well as co-investigator on the Science of Generosity Initiative, and co-author of American Generosity: Who Gives and Why (OUP 2016).

Song Yang is a professor in the Department of Sociology and Criminology at the University of

Arkansas, Fayetteville and co-author with David Knoke of the Sage blue book on Social Network Analysis. Yang's research investigates applications of social network theories and methods in explaining organizational behaviors. 
Table 1. Weighted Descriptive Statistics $(\mathrm{N}=1,977)$

\begin{tabular}{|c|c|c|c|c|}
\hline & Mean / Prop. & SD & Min. & Max. \\
\hline Charitable Giver (Outcome) & 0.552 & 0.497 & 0 & 1 \\
\hline \multicolumn{5}{|l|}{ Covariate Measures } \\
\hline Female & 0.512 & 0.500 & 0 & 1 \\
\hline Age & 48.69 & 15.55 & 23 & 102 \\
\hline \multicolumn{5}{|l|}{ Race/Ethnicity } \\
\hline White & 0.700 & 0.458 & 0 & 1 \\
\hline Black (REF) & 0.107 & 0.309 & 0 & 1 \\
\hline Hispanic & 0.128 & 0.334 & 0 & 1 \\
\hline Other & 0.065 & 0.246 & 0 & 1 \\
\hline Married & 0.636 & 0.481 & 0 & 1 \\
\hline Youth in Household & 0.303 & 0.460 & 0 & 1 \\
\hline Homeowner & 0.744 & 0.437 & 0 & 1 \\
\hline Employed & 0.565 & 0.496 & 0 & 1 \\
\hline Household Income & 11.14 & 4.370 & 1 & 19 \\
\hline College Degree & 0.371 & 0.483 & 0 & 1 \\
\hline \multicolumn{5}{|l|}{ Religious Service Frequency } \\
\hline Never (REF) & 0.345 & 0.476 & 0 & 1 \\
\hline Yearly & 0.302 & 0.459 & 0 & 1 \\
\hline Monthly & 0.088 & 0.283 & 0 & 1 \\
\hline Weekly+ & 0.263 & 0.440 & 0 & 1 \\
\hline \multicolumn{5}{|l|}{ Political Party Affiliation } \\
\hline Republican & 0.253 & 0.435 & 0 & 1 \\
\hline Democrat & 0.348 & 0.477 & 0 & 1 \\
\hline Independent & 0.194 & 0.395 & 0 & 1 \\
\hline No Political Party Affiliation (REF) & 0.205 & 0.404 & 0 & 1 \\
\hline Metropolitan Area Residence & 0.831 & 0.375 & 0 & 1 \\
\hline \multicolumn{5}{|c|}{ Social Capital \& Social Network Measures } \\
\hline Social Trust & 4.135 & 1.530 & 1 & 7 \\
\hline Social Network Size & 3.763 & 1.724 & 0 & 5 \\
\hline Giver in Social Network & 0.640 & 0.480 & 0 & 1 \\
\hline Asked by Social Network & 0.318 & 0.466 & 0 & 1 \\
\hline Asks of Social Network & 0.275 & 0.446 & 0 & 1 \\
\hline Alter 1 & 0.916 & 0.278 & 0 & 1 \\
\hline Alter 2 & 0.909 & 0.287 & 0 & 1 \\
\hline Alter 3 & 0.900 & 0.300 & 0 & 1 \\
\hline Alter 4 & 0.887 & 0.316 & 0 & 1 \\
\hline Alter 5 & 0.875 & 0.331 & 0 & 1 \\
\hline Alter 1 - Giver & 0.424 & 0.494 & 0 & 1 \\
\hline Alter 1 - Asked & 0.195 & 0.396 & 0 & 1 \\
\hline Alter 1 - Asks & 0.192 & 0.394 & 0 & 1 \\
\hline
\end{tabular}

Source: Science of Generosity Survey 2010 
Table 2. Logistic Regression of Charitable Giving, Unstandardized Coefficients

\begin{tabular}{|c|c|c|c|c|}
\hline & Model 1 & Model 2 & Model 3 & Model 4 \\
\hline Female & $0.319^{*}$ & $0.332^{*}$ & 0.236 & $0.330^{*}$ \\
\hline [Reference: Female] & $(0.138)$ & $(0.138)$ & $(0.141)$ & $(0.148)$ \\
\hline \multirow[t]{2}{*}{ Age } & $0.0147 * *$ & $0.0134 * *$ & 0.0101 & $0.0114 *$ \\
\hline & $(0.00508)$ & $(0.00517)$ & $(0.00516)$ & $(0.00529)$ \\
\hline Race-White & 0.385 & 0.325 & 0.335 & 0.372 \\
\hline [Reference: Black] & $(0.249)$ & $(0.247)$ & $(0.251)$ & $(0.260)$ \\
\hline \multirow[t]{2}{*}{ Race-Hispanic } & -0.0221 & -0.0824 & -0.0446 & 0.0298 \\
\hline & $(0.302)$ & $(0.298)$ & $(0.299)$ & $(0.313)$ \\
\hline \multirow[t]{2}{*}{ Race-Other } & -0.282 & -0.342 & -0.347 & -0.291 \\
\hline & $(0.389)$ & $(0.392)$ & $(0.397)$ & $(0.414)$ \\
\hline \multirow[t]{2}{*}{ Married } & 0.110 & 0.117 & 0.108 & 0.136 \\
\hline & $(0.160)$ & $(0.161)$ & $(0.163)$ & $(0.172)$ \\
\hline \multirow[t]{2}{*}{ Youth in Household } & 0.238 & 0.253 & 0.263 & 0.255 \\
\hline & $(0.178)$ & $(0.179)$ & $(0.183)$ & $(0.189)$ \\
\hline \multirow[t]{2}{*}{ Homeowner } & 0.189 & 0.174 & 0.183 & 0.231 \\
\hline & $(0.170)$ & $(0.170)$ & $(0.172)$ & $(0.178)$ \\
\hline \multirow[t]{2}{*}{ Employed } & 0.0296 & 0.0135 & 0.0184 & 0.0845 \\
\hline & $(0.156)$ & $(0.157)$ & $(0.159)$ & $(0.165)$ \\
\hline \multirow[t]{2}{*}{ Household Income } & $0.0859 * * *$ & $0.0836 * * *$ & $0.0758 * * *$ & $0.0810 * * *$ \\
\hline & $(0.0201)$ & $(0.0200)$ & $(0.0201)$ & $(0.0210)$ \\
\hline \multirow[t]{2}{*}{ College Degree } & $0.459 * *$ & $0.452 * *$ & $0.415^{* *}$ & $0.391 *$ \\
\hline & $(0.153)$ & $(0.154)$ & $(0.155)$ & $(0.161)$ \\
\hline Religious Services - Yearly & 0.301 & 0.289 & 0.271 & 0.197 \\
\hline [Reference: Never] & $(0.174)$ & $(0.175)$ & $(0.179)$ & $(0.183)$ \\
\hline \multirow{2}{*}{ Religious Services - Monthly } & -0.129 & -0.139 & -0.159 & -0.135 \\
\hline & $(0.255)$ & $(0.256)$ & $(0.257)$ & $(0.267)$ \\
\hline \multirow[t]{2}{*}{ Religious Services - Weekly+ } & $0.384 *$ & $0.362 *$ & 0.286 & 0.297 \\
\hline & $(0.181)$ & $(0.181)$ & $(0.182)$ & $(0.191)$ \\
\hline Political Party-Republican & 0.289 & 0.283 & 0.287 & 0.268 \\
\hline \multirow{3}{*}{$\begin{array}{l}\text { [Reference: No Affiliation] } \\
\text { Political Party-Democrat }\end{array}$} & $(0.211)$ & $(0.212)$ & $(0.217)$ & $(0.220)$ \\
\hline & $0.482 *$ & $0.449 *$ & $0.414^{*}$ & $0.430^{*}$ \\
\hline & $(0.198)$ & $(0.198)$ & $(0.202)$ & $(0.209)$ \\
\hline \multirow[t]{2}{*}{ Political Party-Independent } & 0.398 & 0.389 & 0.374 & 0.398 \\
\hline & $(0.209)$ & $(0.209)$ & $(0.213)$ & $(0.222)$ \\
\hline \multirow{2}{*}{ Metropolitan Area Residence } & 0.183 & 0.207 & 0.217 & 0.309 \\
\hline & $(0.191)$ & $(0.191)$ & $(0.195)$ & $(0.196)$ \\
\hline \multirow[t]{2}{*}{ Social Trust } & & $0.0950 *$ & 0.0741 & 0.0750 \\
\hline & & $(0.0472)$ & $(0.0490)$ & $(0.0503)$ \\
\hline \multirow[t]{2}{*}{ Social Network Size $(0-5+)$} & & & $0.170 * * *$ & 0.0986 \\
\hline & & & $(0.0438)$ & $(0.0554)$ \\
\hline \multirow[t]{2}{*}{ Constant } & $-2.974 * * *$ & $-3.212 * * *$ & $-3.607 * * *$ & $-3.573 * * *$ \\
\hline & $(0.448)$ & $(0.460)$ & $(0.490)$ & $(0.529)$ \\
\hline Observations & 1,977 & 1,977 & 1,977 & 1,840 \\
\hline
\end{tabular}

Source: Science of Generosity Survey 2010

Notes: Standard errors in parentheses; $* * * \mathrm{p}<0.001, * * \mathrm{p}<0.01, * \mathrm{p}<0.05$ 
Table 3. Logistic Regression of Charitable Giving \& Social Network Exposure to Charitable Giving, Being Asked to Give, or Asking Others to Give to Charitable Causes

\begin{tabular}{lllll}
\hline & Model 1 & Model 2 & Model 3 & Model 4 \\
\hline Female & $0.348^{*}$ & $0.378^{* *}$ & $0.359^{*}$ & $0.350^{*}$ \\
Age & $(0.148)$ & $(0.145)$ & $(0.145)$ & $(0.148)$ \\
& $0.0134^{*}$ & $0.0126^{*}$ & $0.0132^{*}$ & $0.0130^{*}$ \\
Household Income & $(0.00533)$ & $(0.00543)$ & $(0.00536)$ & $(0.00545)$ \\
& $0.0808^{* * *}$ & $0.0857^{* * *}$ & $0.0843^{* * *}$ & $0.0816^{* * *}$ \\
College Degree & $(0.0211)$ & $(0.0209)$ & $(0.0210)$ & $(0.0211)$ \\
& $0.358^{*}$ & $0.387^{*}$ & $0.388^{*}$ & $0.364^{*}$ \\
Political Party-Democrat & $(0.163)$ & $(0.161)$ & $(0.160)$ & $(0.162)$ \\
& $0.422^{*}$ & $0.443^{*}$ & $0.431^{*}$ & $0.428^{*}$ \\
Social Trust & $(0.211)$ & $(0.208)$ & $(0.209)$ & $(0.211)$ \\
& $0.422^{*}$ & $0.443^{*}$ & $0.431^{*}$ & $0.428^{*}$ \\
Giving in Social Network & $(0.211)$ & $(0.208)$ & $(0.209)$ & $(0.211)$ \\
& $0.619^{* * *}$ & & & $0.493^{* *}$ \\
Asked by Social Network to Give & $(0.153)$ & & & $(0.168)$ \\
& & $0.537^{* *}$ & & 0.289 \\
Asks Social Network to Give & & $(0.166)$ & & $(0.205)$ \\
& & & $0.453^{* *}$ & 0.124 \\
Constant & & & $(0.166)$ & $(0.202)$ \\
Observations & $-3.367^{* * *}$ & $-3.342^{* * *}$ & $-3.300^{* * *}$ & $-3.398^{* * *}$ \\
\hline
\end{tabular}

Source: Science of Generosity Survey 2010

Notes: Standard errors in parentheses; ${ }^{* * *} \mathrm{p}<0.001,{ }^{* *} \mathrm{p}<0.01,{ }^{*} \mathrm{p}<0.05$; only significant measures shown. 
Table 4. Logistic Regression of Charitable Giving \& Social Network Alters

\begin{tabular}{lllll}
\hline Statistically Significant Covariates & Model 1 & Model 2 & Model 3 & Model 4 \\
Household Income & $0.0723^{* *}$ & $0.0792^{* *}$ & $0.0808^{* *}$ & $0.0826^{* * *}$ \\
& $(0.0264)$ & $(0.0260)$ & $(0.0260)$ & $(0.0210)$ \\
College Degree & $0.506^{*}$ & $0.560^{* *}$ & $0.536^{*}$ & $0.364^{*}$ \\
& $(0.211)$ & $(0.210)$ & $(0.210)$ & $(0.160)$ \\
Political Party-Democrat & $0.576^{*}$ & $0.560^{*}$ & $0.568^{*}$ & $0.455^{*}$ \\
& $(0.261)$ & $(0.262)$ & $(0.267)$ & $(0.208)$ \\
Political Party-Independent & $0.558^{*}$ & $0.587^{*}$ & $0.593^{*}$ & 0.349 \\
& $(0.284)$ & $(0.280)$ & $(0.285)$ & $(0.220)$ \\
Social Trust & $0.156^{*}$ & $0.145^{*}$ & $0.144 *$ & 0.0767 \\
& $(0.0644)$ & $(0.0641)$ & $(0.0628)$ & $(0.0497)$ \\
\hline Alter 1 - Gives & $0.433^{*}$ & & & $0.374^{*}$ \\
Alter 1 - Asked & $(0.217)$ & & & $(0.165)$ \\
Alter 3 - Asks & & $0.520^{*}$ & & 0.334 \\
& & $(0.250)$ & & $(0.232)$ \\
\hline Constant & & & $-0.692^{*}$ & \\
Observations & $-3.371^{* * *}$ & $-3.473^{* * *}$ & $-3.393^{* * *}$ & \\
\hline
\end{tabular}

Source: Science of Generosity 2010

Notes: Standard errors in parentheses; $* * * \mathrm{p}<0.001,{ }^{*} \mathrm{p}<0.01,{ }^{*} \mathrm{p}<0.05$; Only significant measures shown. 
Table 5. Logistic Regression of Charitable Giving \& Alter 1 Doing and Asking Scenarios

\begin{tabular}{|c|c|}
\hline Statistically Significant Covariates & Model 1 \\
\hline Female & $\begin{array}{l}0.387 * * \\
(0.147)\end{array}$ \\
\hline Age & $0.0119^{*}$ \\
\hline Household Income & $\begin{array}{l}(0.00527) \\
0.0821 * * * \\
(0.0211)\end{array}$ \\
\hline College Degree & $\begin{array}{l}0.378 * \\
(0.160)\end{array}$ \\
\hline Political Party-Democrat & $\begin{array}{l}0.470^{*} \\
(0.208)\end{array}$ \\
\hline \multicolumn{2}{|l|}{ Alter 1 Giving and Asking Scenarios } \\
\hline $\begin{array}{l}\text { Scenario 1: Alter Gives-Alter Asks-Ego Asks } \\
\text { Alter Gives and Mutual Asking }\end{array}$ & $\begin{array}{l}0.606^{*} \\
(0.257)\end{array}$ \\
\hline $\begin{array}{l}\text { Scenario 2: Alter Gives-Alter Asks-No Ego Ask } \\
\text { Alter Gives and Alter Asks }\end{array}$ & $\begin{array}{l}0.821^{*} \\
(0.327)\end{array}$ \\
\hline $\begin{array}{l}\text { Scenario 3: Alter Gives-No Alter Ask-Ego Asks } \\
\text { Alter Gives and Ego Asks }\end{array}$ & $\begin{array}{l}0.499 \\
(0.330)\end{array}$ \\
\hline $\begin{array}{l}\text { Scenario 4: Alter Gives-No Alter Ask-No Ego Ask } \\
\text { Alter Gives and No Asking }\end{array}$ & $\begin{array}{l}0.518 * * \\
(0.188)\end{array}$ \\
\hline $\begin{array}{l}\text { Scenario 5: Non-Giving Alter-No Alter Ask-No Ego Ask } \\
\text { Non-Giving Alter, Mutual Asking }\end{array}$ & $\begin{array}{l}0.850 \\
(0.495)\end{array}$ \\
\hline $\begin{array}{l}\text { Scenario 6: Non-Giving Alter-Alter Asks-No Ego Ask } \\
\text { Non-Giving Alter, Alter Asks }\end{array}$ & $\begin{array}{l}1.122 \\
(0.699)\end{array}$ \\
\hline $\begin{array}{l}\text { Scenario 7: Non-Giving Alter-No Alter Ask-Ego Asks } \\
\text { Non-Giving Alter, Ego Asks }\end{array}$ & $\begin{array}{l}0.673 \\
(0.465)\end{array}$ \\
\hline $\begin{array}{l}\text { Scenario 8: Non-Giver-No Alter Ask-No Ego Ask } \\
\text { [Reference: Non-Giving Alter, No Asking] }\end{array}$ & ------- \\
\hline Constant & $\begin{array}{l}-3.335^{* * *} \\
(0.499)\end{array}$ \\
\hline Observations & 1,840 \\
\hline
\end{tabular}

Source: Science of Generosity 2010

Notes: Standard errors in parentheses; ${ }^{* *} \mathrm{p}<0.001,{ }^{* *} \mathrm{p}<0.01,{ }^{*} \mathrm{p}<0.05$; Only significant measures shown. 